\title{
PRODUÇÃO DE FRUTOS DE POPULAÇÕES NATURAIS DE PEQUIZEIRO NO ESTADO DE GOIÁS ${ }^{1}$
}

\author{
GISLENE AUXILIADORA FERREIRA², RONALDO VELOSO NAVES ${ }^{3}$, LÁZARO JOSÉ CHAVES ${ }^{4}$, \\ VALQUÍRIA DA ROCHA SANTOS VELOSO ${ }^{5}$, ELI REGINA BARBOZA DE SOUZA ${ }^{6}$
}

RESUMO - O pequizeiro é uma espécie nativa do Cerrado de importância econômica e cultural para o Brasil Central. O cultivo dessa frutífera é uma forma de diminuir a pressão extrativista sobre o ambiente natural, mas ainda há necessidade de técnicas que viabilizem a implantação, condução e colheita dos frutos. O trabalho teve como objetivo caracterizar a influência de caracteres da planta, do ambiente e da entomofauna sobre a produção de pequizeiros de ocorrência natural, em cinco regiões do Estado de Goiás, em três anos. Foram caracterizadas quinze populações de pequizeiros quanto à biometria, à produção e ao ambiente de ocorrência, assim como a organismos associados às plantas. A produção do pequizeiro, em três anos, diferiu significativamente no Estado de Goiás, apresentando média de 132 frutos por planta e produção por área projetada da copa de 1,64 frutos $\mathrm{m}^{-2}$. As três populações mais produtivas apresentam como características comuns o vigor, por estarem localizadas em ambiente aberto e por apresentarem início da copa mais próxima do solo. Há um elevado grupo de organismos que interagem com o pequizeiro, destacando-se os insetos, os fungos e as aves (araras), que podem interferir na produção. Conclui-se que a produção do pequizeiro no Estado de Goiás apresenta grande variabilidade entre safras, plantas e populações, sendo geralmente baixa, porém existem plantas promissoras para futuros programas de melhoramento.

Termos para Indexação: Caryocar brasiliense, Cerrado, frutas nativas, pequi, recursos genéticos.

\section{PRODUCTION OF FRUITS FROM NATURAL POPULATIONS OF PEQUI TREES IN THE STATE OF GOIÁS, BRAZIL}

\begin{abstract}
The pequi tree is a native species from the Brazilian Cerrado (Neotropical Savanna) with economic and cultural importance for local human population, needing however, techniques that make possible the implantation of orchards, its conduction and the harvest of fruits, as a tool for reducing the pressure on the natural environment, as well as the maintenance of the regional culture. The present study aimed to characterize the production of pequi trees of natural occurrence in fifteen dispersed populations in five regions of the state of Goiás, Brazil. The "Pequizeiro" differed significantly in three years of production in the State of Goiás, with an average of 132 fruits per plant and yield of the projected area of the canopy of 1.64 fruits $\mathrm{m}^{-2}$. The three most productive populations have characteristics in common as the vigor by being located in an open environment and by presenting the beginning of the canopy closer to the ground. It is concluded that the production of "pequizeiro" in the state of the Goiás, shows great variability among crops, plants and populations, usually low, but there are promising plants for future breeding programs.

Index terms: Caryocar brasiliense, Savanna, native fruit, "pequi”, genetic resources.
\end{abstract}

${ }^{1}$ (Trabalho 404-13). Recebido em: 16-10-2013. Aceito para publicação em: 16-10-2014.

${ }^{2}$ Eng. Agra.Dra. Escola de Agronomia - UFG. Escola de Agronomia/UFG, Rod. Goiânia/Nova Veneza km 0. Goiânia-GO. E-mail: gislene_ferreira@ufg.br

${ }^{3}$ Eng. Agr.Dr. Escola de Agronomia - UFG. E-mail: ronaldo@ufg.br

${ }^{4}$ Eng. Agr.Dr. Escola de Agronomia - UFG. E-mail: 1chaves@ufg.br

${ }^{5}$ Eng. Agra.Dra. Escola de Agronomia - UFG . E-mail: valquiriaufg@gmail.com

${ }^{6}$ Eng.Agra.Dra. Escola de Agronomia - UFG. E-mail: eliregina1@gmail.com 


\section{INTRODUÇÃO}

Dentre as espécies que compõem a flora do Cerrado, as frutíferas ocupam lugar de destaque pelas suas qualidades nutricionais, aspectos culturais e potencialidade de exploração econômica. Destas, destaca-se o pequizeiro (Caryocar brasiliense Camb.), que é uma fruteira nativa muito utilizada pela população regional (VERA et al., 2007), e que vem sendo estudada com vistas à seleção de procedências e progênies com melhor desenvolvimento em condições de cultivo (MOURA et al., 2013b).

A espécie C. brasiliense ocorre no domínio do Cerrado do Brasil Central, em fitofisionomias de cerradão, cerrado sentido restrito, cerrado ralo e no cerrado rupestre (RIBEIRO; WALTER, 2008). É uma árvore que pode atingir até $8 \mathrm{~m}$ de altura ou apresentar porte pequeno devido à baixa fertilidade do solo ou a fatores genéticos. Possui caule espesso, ramos grossos e angulosos, com perda das folhas na estação seca, intensificando-se no mês de junho ou julho, coincidindo com a emissão de folhas novas e botões florais (SANTANA; NAVES, 2003; VILELA et al., 2008).

$\mathrm{O}$ volume de frutos de pequi comercializados, registrado pela estatística oficial de Goiás e Minas Gerais, oscila consideravelmente a cada ano. Foram comercializados na Central de Abastecimento de Goiás, nos anos de 2009, 2010 e2011, respectivamente, $3.875 ; 5.264$ e 5.550 toneladas. Desse total, a média percentual de frutas provenientes do Estado de Goiás foi de 44,72\% (CEASA, 2011). Grande parte dos frutos de pequi comercializados no Centro-Oeste não são quantificados, devido ao comércio informal, sendo toda a produção proveniente de extrativismo.

$\mathrm{O}$ extrativismo intensivo do pequizeiro pode gerar perdas de material genético, pois quase todos os frutos de qualidade, originados de genótipos superiores, são coletados e consumidos ou comercializados, o que impede a reprodução natural a partir desses frutos (MELO JÚNIOR et al., 2004). Dessa forma, a caracterização da variabilidade da produção de frutos das populações nativas de pequizeiro torna-se necessária como estratégia agronômica de conservação e manejo da espécie, possibilitando, assim, a viabilização do extrativismo sustentável, tanto quanto a implantação de pomares.

Tendo em vista a importância socioeconômica do pequizeiro para o Brasil Central e a necessidade de técnicas que viabilizem sua implantação, condução e colheita em pomares comerciais, visando a reduzir a pressão sobre o ambiente natural, o presente trabalho teve como objetivo caracterizar a produção de pequizeiros de ocorrência natural em cinco regiões do Estado de Goiás, bem como levantar possíveis fatores impactantes sobre a produção.

\section{MATERIAL E MÉTODOS}

O estudo foi realizado em quinze populações naturais de pequizeiros, de cinco regiões do Estado de Goiás (Figura 1). Para a escolha, foram realizadas viagens de prospecção aos principais municípios fornecedores de pequi para as Centrais de Abastecimento do Estado de Goiás (CEASA-GO). $\mathrm{O}$ critério de seleção das populações considerou a dispersão espacial, a produção de frutos, o diâmetro basal das plantas (SANTANA; NAVES, 2003) e a nucleação das árvores em cada população, com raio máximo de $300 \mathrm{~m}$. Desta forma, a maior distância entre duas plantas de uma mesma população não ultrapassou 600 metros.

Em cada uma das cinco regiões estudadas, foram selecionadas três populações, cada uma com 15 plantas avaliadas, totalizando 225 plantas adultas, das quais 223 foram aproveitadas para tomada de dados. As plantas possuíam desenvolvimento distinto e situavam-se em ambientes diferentes, com variado grau de antropização. Nas áreas totalmente antropizadas, as plantas em estudo constituíam os últimos remanescentes da vegetação natural.

As avaliações foram realizadas em áreas com características climáticas típicas de Cerrado, que apresentam a configuração mesoclimática da microrregião, caracterizada pelo tipo Aw, tropical semiúmido, quente, com estação seca bem definida, no período de maio a setembro. Os menores índices pluviométricos ocorrem nas regiões norte e nordeste do Estado (1.200-1.400 mm anuais), com gradiente crescente no sentido leste-oeste. Os maiores índices estão na faixa de 1.500 a $1.800 \mathrm{~mm}$ anuais. Os valores de temperatura média anual no Cerrado situam-se entre $22^{\circ} \mathrm{C}$, ao sul, e $26^{\circ} \mathrm{C}$, ao norte (LOBATO et al., 2002).

Realizou-se a classificação sucinta dos solos, caracterizaram-se a declividade e o relevo da região, sendo retirada uma amostra composta de solos na camada de $0 \mathrm{~m}$ a $0,20 \mathrm{~m}$ de profundidade, na área de cada população. Cada amostra foi composta por 10 subamostras, obtidas sob a copa dos pequizeiros, para a avaliação da textura do solo.

As avaliações foram realizadas entre os meses de setembro e dezembro, em três anos (2004, 2005 e 2006), correspondendo ao período de produção de frutos do pequizeiro, por meio de visitas às plantas nas áreas predefinidas. Para a caracterização biométrica das plantas, foram medidos o diâmetro do 
tronco na altura da base (DAB, a $10 \mathrm{~cm}$ do solo) e o diâmetro à altura do peito (DAP, a 1,30 $\mathrm{m}$ do solo), a altura total da planta, a altura média da copa até o solo (média dos quatro quadrantes) e a projeção da copa no solo, nos sentidos leste-oeste e norte-sul. A partir destas variáveis, foram calculadas a altura da copa e a área de projeção da copa no solo. O número de frutos por metro quadrado foi obtido pela divisão da produção de frutos por planta pela área de projeção de copa no solo.

A contagem do número de frutos por planta foi realizada no período de setembro a dezembro de cada ano, levando-se em conta a época de amadurecimento dos frutos em cada região do Estado de Goiás: norte (setembro/outubro), noroeste (outubro/novembro), oeste (novembro/dezembro), sudeste/sul e nordeste (dezembro/janeiro), assim como o número de sementes por fruto. As avaliações foram realizadas de quinze a trinta dias antes da maturação dos frutos, pois nestas condições os frutos estavam plenamente desenvolvidos e ainda nas plantas. A contagem de frutos foi realizada por três avaliadores treinados, considerando-se todos os frutos com diâmetro acima de 3,0 cm. Quando havia resultados discrepantes, procedia-se a nova contagem. Posteriormente, calculava-se a média do número de frutos contados pelos avaliadores. Mantiveram-se os mesmos avaliadores em todas as populações e nos três anos de avaliação.

Para a análise dos dados, utilizou-se da estatística descritiva e da análise de variância, realizada segundo o modelo hierárquico, que considera os efeitos de regiões, população dentro de regiões e plantas dentro de populações. $\mathrm{O}$ modelo matemático empregado foi: $Y_{i j k}=m+r_{i}+a_{j(i)}+p_{k(i)}$ em que: $Y_{i j k}$ é o valor observado na planta $k$, da população $j$, da região $i$; $m$ é o efeito da média geral; $r_{i}$ é o efeito fixo da região $i ; a_{j(i)}$ é o efeito aleatório da população $j$, da região $i$; e $p_{k(i j)}$ é o efeito aleatório da planta $k$, da população $j$, da região $i$. A análise de variância foi realizada para a verificação da significância dos diferentes efeitos do modelo. Foram estimados, ainda, coeficientes de correlação entre as diferentes variáveis.

\section{RESULTADOS E DISCUSSÃO}

Os solos predominantes que sustentam as 15 populações de pequizeiros estudadas são das classes Latossolos (5), Cambissolo (4), Neossolo Quartzarênico (4) e Plintissolo Pétrico Concrecionário (2).

A textura do solo em estudo apresentou teor de argila de $11 \%$ a $41 \%$, silte de $1 \%$ a $13 \%$ e areia de $46 \%$ a $87 \%$. Esses valores expressam a elevada plasticidade do pequizeiro, ocorrendo desde solos com quantidade de areia elevada até aqueles com alto teor de argila, vegetando e produzindo frutos. Essa grande plasticidade da planta foi observada, também, por Santana e Naves (2003), em ambientes naturais do Estado de Goiás.

O relevo do solo predominante nas áreas com populações de pequizeiro foi suave ondulado, com declividade variando de $0 \%$ a $9 \%$, sendo a população de pequizeiros de Caldas Novas aquela que ocupava área com declive mais acentuado.

A produção média de frutos das 223 plantas, durante três anos, foi de 132 frutos por planta, com variação entre zero e 2.160 , sendo que a média foi de, respectivamente, 83; 109 e 205 frutos por planta em 2004, 2005 e 2006, sendo a diferença de produção entre os anos significativa (Tabela 1). Santana e Naves (2003) observaram valor médio de 25 frutos por planta, com máximo de 351 frutos por planta, na região sudeste do Estado de Goiás. Ressalte-se que a produção de polpa de pequi, que é o principal produto aproveitável, depende, além do número de frutos por planta, da massa média de frutos e do rendimento de polpa. Estas variáveis também podem variar consideravelmente entre populações e entre plantas (VERA et al., 2007; CORRÊA et al., 2008; MOURA et al., 2013a); mesmo assim, o número de frutos oferece um bom indicador do potencial produtivo das plantas.

As populações que apresentaram as maiores produções médias de frutos por planta foram as de Estrela do Norte (350), Mambaí (256), Araguapaz I (218) e Hidrolândia (208) (Tabela 1). Em 2004 e 2005, as produções médias foram menores em relação a 2006, em dez das quinze populações estudadas, com aumento expressivo neste último ano. Esses dados confirmam que o pequizeiro apresenta acentuadas variações na produção entre anos.

Com relação aos valores encontrados para os dados biométricos das plantas de pequizeiro (Tabela 2), deve-se considerar que um dos critérios para a seleção das plantas de cada população foi ser produtiva e com maior diâmetro. Portanto, as plantas eram as maiores em sua área de ocorrência. Isto faz com que esses valores possam estar superestimados e acima dos encontrados por Santana e Naves (2003). O DAP médio das plantas variou de $0,12 \mathrm{~m}$ a $0,72 \mathrm{~m}$, com $58 \%$ das plantas entre $0,2 \mathrm{~m}$ e $0,4 \mathrm{~m}$.

A área média de projeção da copa dos pequizeiros foi de $83,34 \mathrm{~m}^{2}$. Considerando que as plantas tendem a produzir na periferia da copa e que necessitam de insolação direta sobre as copas para produzirem, seria recomendável que o 
espaçamento entre plantas de pé-franco não fosse inferior ao correspondente a $100 \mathrm{~m}^{2}$ por planta. Outra possibilidade seria a execução de podas de contenção, o que precisa ser avaliado experimentalmente.

A análise conjunta de variância, nos três anos consecutivos, mostrou diferenças altamente significativas (Tabela 3). Houve interação significativa entre populações e anos, indicando uma mudança relativa da produção de frutos, a cada ano. Pode-se afirmar que os efeitos dos anos influenciaram sobre as diferentes populações, sendo que a interação de populações com anos foi devida à interação de anos com as regiões e não com as populações dentro de regiões. Isto confirma que diferenças ambientais importantes ocorrem nas regiões, provavelmente fatores climáticos, como precipitação e temperatura.

A análise de variância para a produção de frutos revelou existência de variação significativa entre populações, nos três anos estudados (Tabela 4). O desdobramento deste efeito mostrou não significância para a variação entre regiões e variação significativa entre populações dentro de regiões. Este fato mostra que as condições locais, mais que as diferenças entre regiões, interferem na produção, o que pode ser verificado pelas produções médias de cada área de uma mesma região (Tabela 1). Destacase, na região nordeste, a população de Mambaí, cuja produção foi, em média, de 256 frutos por planta, enquanto em Alvorada do Norte foi de apenas 8 frutos por planta. A população de Alvorada do Norte encontra-se inserida em cerrado pouco antropizado, com presença de árvores frondosas, com aspecto de plantas mais velhas, além de sinal de ataque severo de formigas cortadeiras.

Em populações alógamas, espera-se maior proporção da variação genética dentro de populações, em comparação com a variação entre populações. Além dos fatores genéticos, a variação dos fatores ambientais, além da variação nas idades das plantas, também pode ter contribuído para o padrão observado. O maior coeficiente de variação ocorreu na área de menor produção de frutos, o que é esperado.

$\mathrm{Na}$ análise de populações dentro de regiões, ocorreu variação altamente significativa $(\mathrm{P}<0,01)$ de produção nos anos de 2004 e 2006. No ano de 2005 , a variação foi menor, embora significativa $(\mathrm{P}<0,05)$, o que pode ser explicado pela redução do número de frutos nas populações mais produtivas, como Mambaí e Estrela do Norte, e manutenção da produção nas áreas menos produtivas.

A diferença entre plantas dentro de populações não pôde ser testada estatisticamente por ser o menor nível hierárquico de variação. Entretanto, o alto coeficiente de variação médio observado (158,29\%) mostra a grande magnitude da variação entre plantas, o que é esperado para espécies alógamas. Os resultados do presente trabalho foram utilizados para selecionar populações e matrizes mais produtivas para coleta de germoplasma de pequizeiros do Cerrado (MOURA et al., 2013a; MOURA et al., 2013b).

Os coeficientes de correlação entre caracteres foram, em sua maioria, positivos e significativos (Tabela 5). A exceção foi a correlação negativa entre número de frutos por planta (NFP) e altura do início da copa (AIC), significativa quando se considera o total de plantas, e não significativa quando se consideram plantas dentro de regiões. Merece destaque, também, a correlação positiva e significativa do número de frutos (NFP) com a área de projeção da copa (APC). Esses resultados mostram que copas mais baixas e ramificadas lateralmente estão associadas às plantas mais produtivas, o que pode servir de guia para a realização de podas de formação em pequizeiros cultivados. Os maiores coeficientes de correlação, como esperado, ocorreram entre as variáveis relacionadas ao porte da planta (DAB, DAP, ATP e APC).

O número de sementes (pirênios) observado variou de 1 a 5 sementes por fruto. Em 69,13\%, ocorreu uma semente por fruto; em $28,63 \%$, duas sementes e em $2,24 \%$,três sementes, obtendo-se a média ponderada de 1,46 pirênio por fruto, valor pouco inferior ao observado por Vera et al. (2007), que foi de 1,51 pirênio por fruto.

A área de projeção da copa variou de $9,62 \mathrm{~m}^{2}$ a $297,12 \mathrm{~m}^{2}$, com as maiores médias nas populações de Alvorada do Norte, Araguapaz II e Mambaí. A população de Alvorada do Norte encontra-se em cerradão com presença de gado. As populações de Araguapaz II e Mambaí encontram-se em pastagens, portanto ambientes abertos favorecem o desenvolvimento das plantas de pequizeiros.

A vegetação natural nas áreas é constituída por remanescentes de "cerrado sentido restrito" e "cerradão", pequenos fragmentos de cerrado sentido restrito ou constituindo os pequizeiros em estudo os únicos exemplares da flora original. A eliminação da vegetação nativa observada neste trabalho retrata o progressivo desmatamento no Estado de Goiás observado por Santana e Naves (2003), entre outros.

Nas dez plantas mais frondosas, isto é, com maior projeção de copa, encontraram-se, no máximo, 11,9 frutos $\mathrm{m}^{-2}$, inclusive com a presença de uma árvore com 0,1 fruto $\mathrm{m}^{-2}$, oriunda de uma população que apresentou produção muito baixa de frutos e, no entanto, com maior média de área de projeção 
da copa $\left(127,61 \mathrm{~m}^{2}\right)$. Borges et al. (2012) avaliaram a amostragem aleatória de ramos para quantificar a produção de frutos de $C$. brasiliense, pela dificuldade em quantificar a produção de frutos visualmente, sem recorrer à derrubada da árvore ou dos frutos.

Nas plantas mais produtivas, essa relação alcançou até 33,5 frutos $\mathrm{m}^{-2}$. Três plantas na população de Estrela do Norte e uma planta em Mambaí, além de frondosas, foram também produtivas com 11,$9 ; 8,4 ; 6,1$ e 6,9 frutos $\mathrm{m}^{-2}$ de projeção de copa, respectivamente.

As plantas mais frondosas, em geral, encontravam-se em ambientes abertos, em áreas com pastagens ou lavouras. As plantas que se encontravam em ambientes fechados, isto é, cerrado e cerradão, tenderam a menor produção de frutos, mas com maior possibilidade de originarem novas plantas, no processo de dispersão natural. Este comportamento produtivo do pequizeiro, produzindo mais frutos na periferia da copa e sendo bastante responsivo à luz, tem grande influência sobre a eventual escolha de espaçamento de plantas.

Chama a atenção a grande variação do número de frutos por metro quadrado de projeção de copa do pequizeiro. Essas causas devem ser investigadas no sentido de encontrar procedimentos que possam viabilizar uma produtividade considerada satisfatória. Quando se considera a produção por população (Tabela 4), média de três anos, observa-se que as quatro populações mais produtivas estão em ambientes abertos (Hidrolândia, Mambaí, Estrela do Norte e Araguapaz I); e as quatro populações menos produtivas, em ambientes fechados (Alvorada do Norte, Orizona, Damianópolis e Paraúna).

Doenças como antracnose (Colletotrichum acutatum J. H. Simmonds), caracterizada por pintas nas folhas, foram observadas em todas as plantas. O chicote, ou mal-do-cipó (Phomopsis sp.), foi constatado em todas as populações, em pelo menos uma planta. Mesmo com a expressão dessa doença em alguns galhos da planta, podendo reduzir a produção de frutos, esta não conseguia inibir a produção de forma total. A podridão dos frutos (Lasiodiplodia theobromae (Pat.) Griffone \& Maubl. 1909 e Phomopsis sp.) foi observada em vários municípios, principalmente em Araguapaz I. Anjos et al. (2002) relatam a ocorrência de antracnose em folhas.

Dentre outros representantes da fauna que se alimentam de partes do pequizeiro, destaca-se a araracanindé (Ara ararauna Linnaeus 1758), que tem nas amêndoas do pequi parte de sua dieta alimentar. As aves abrem os frutos ainda em desenvolvimento e retiram sua amêndoa, descartando o restante do fruto.
Estas aves vão de fruto em fruto até danificar parte significativa da produção. Após retirar as amêndoas ou sementes, o exocarpo e o mesocarpo do pequi são descartados pelas araras, servindo de fonte de alimento para as formigas cortadeiras, que retiram todo o exocarpo e o mesocarpo, deixando apenas o endocarpo, que constitui a parte lignificada do fruto.

Dentre as populações avaliadas, as de Caldas Novas, Mambaí e Paraúna destacam-se pela presença da arara-canindé, onde estas aves consomem praticamente toda a produção das plantas que frutificam primeiro. Na população de Paraúna, das quinze plantas estudadas, nove encontravam-se com danos nos frutos, causados pelas araras, no primeiro ano. Na população de Caldas Novas, foi observado que, de quinze plantas, três encontravamse totalmente sem frutos em suas copas, enquanto no solo foram encontradas cascas correspondentes a mais de duzentos frutos por planta, todos com característica de herbivoria recente.

Os locais destacados situam-se próximos de afloramentos calcários rochosos, que constituem o principal local de nidificação dessas aves, sugerindo, assim, que na proximidade dos locais de nidificação, a pressão sobre o pequizeiro seja maior. Essas aves são vorazes e podem contribuir para a redução de frutos viáveis ao mercado. Entretanto, o lado ambiental deve ser ressaltado, uma vez que, nesses locais, o pequi constitui uma das poucas espécies vegetais preservadas que servem de alimento para a arara, necessitando, assim, de mais estudos para estabelecer o equilíbrio e medidas de manejo onde a exploração da produção não seja uma ameaça à manutenção da população destas aves.

Especula-se que a arara, no oeste goiano, tenha uma influência marcante na produção de pequi, uma vez que, nessa região do Estado, não foram realizadas amostragens devido à constante destruição dos frutos por essa ave.

A infestação por erva-de-passarinho (Struthanthus flexicaulis (Mart.) Mart.) (Loranthaceae) foi observada desde ausente a até treze indivíduos por população, variando de uma a dezesseis ervas por planta. As populações com maior infestação foram as de Formoso e Araguapaz I, com treze e onze plantas infestadas por população, respectivamente, com até quatorze ervas por planta. Ervas-de-passarinho são plantas hemiparasitas de outras plantas, sendo dependentes dos pássaros para sua dispersão e debilitam a planta hospedeira (GAZETTA; GALETI 2003).

Ao se pensar na produção do pequizeiro, é necessário observar alguns fatores considerados neste trabalho, dentre os quais se destacam as plantas 
remanescentes em pastagens. Nesse ambiente, a renovação e o estabelecimento de plantas jovens raramente ocorrem, devido ao pastoreio realizado pelos animais e a intervenções com roçagens para a limpeza da pastagem. Outro fator que pode contribuir para a não renovação é a suscetibilidade das plantas à predação nesses ambientes.

Deve-se ressaltar que o gado é presença constante praticamente em todos os locais de ocorrência natural do pequizeiro. Na época das chuvas, outubro a abril, o gado preferencialmente não consome folhas e/ou ramos do pequizeiro; entretanto, no período da seca, de maio a setembro, o gado consome ramos e folhas novas das plantas adultas, contribuindo para aumentar a altura de sua copa. E o mais grave, consumindo totalmente as folhas e os ramos das plantas jovens.

Em seu ambiente natural, o pequizeiro interage com plantas companheiras (SANTANA; NAVES, 2003; MESQUITA et al., 2007), em condições de equilíbrio, apresentando-se rústico; entretanto, sob pressões diversas e fora desse equilíbrio, a planta pode tornar-se vulnerável.

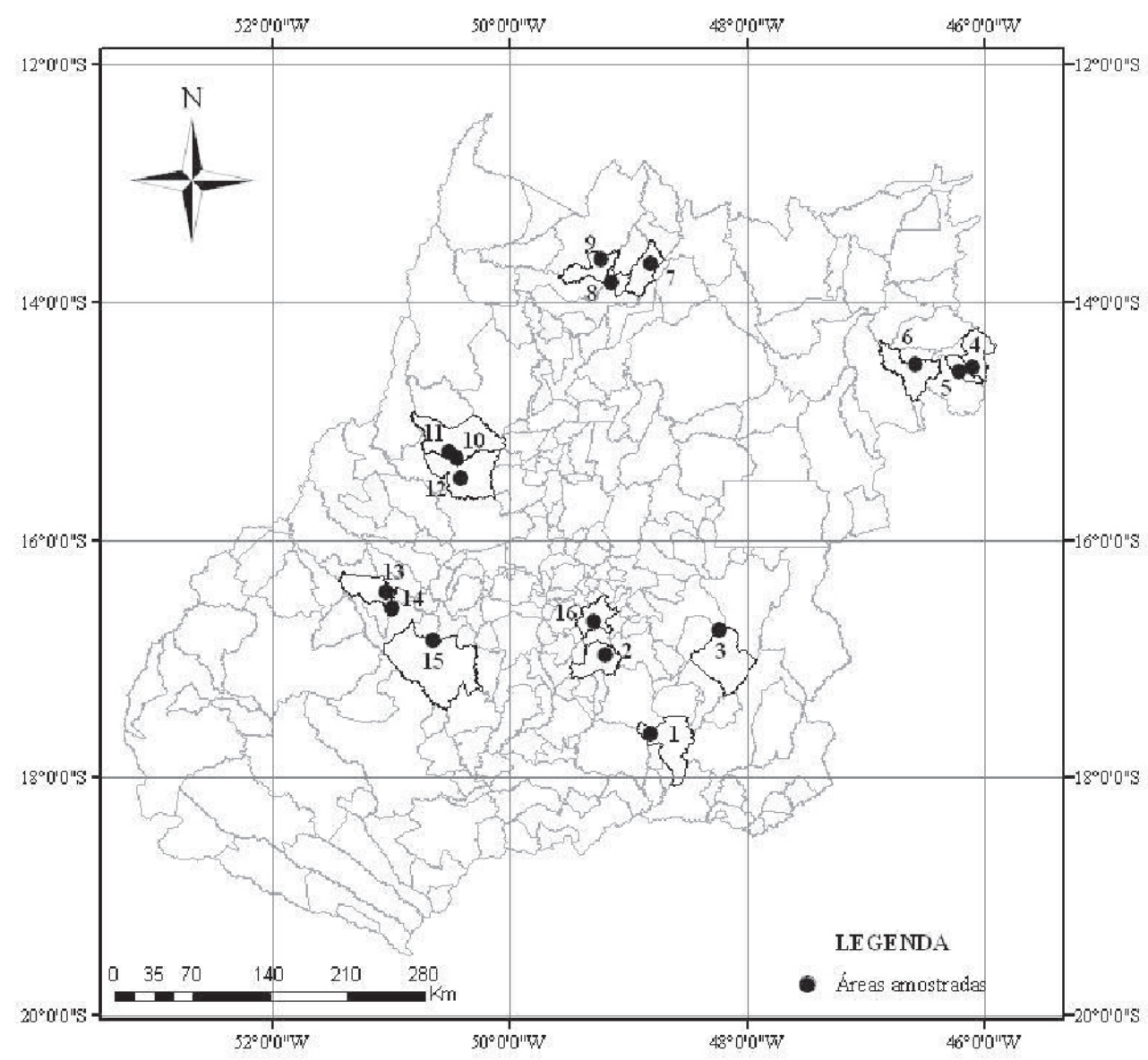

FIGURA 1- Localização das regiões e das populações de pequizeiros (Caryocar brasiliense) estudadas no Estado de Goiás, região sul/sudeste: 1 Caldas Novas; 2 Hidrolandia; 3 Orizona; região nordeste: 4 Mambaí; 5 Damianópolis; 6 Alvorada do Norte; região norte: 7 Formoso; 8 Estrela do Norte; 9 Mutunópolis; região noroeste: 10 Araguapaz I; 11 Araguapaz II; 12 Faina; região oeste: 13 Iporá I; 14 Iporá II e 15 Paraúna. 2007. 
TABELA 1- Produção média, mínima e máxima de quinze populações de pequizeiro (Caryocar brasiliense) do Estado de Goiás, no período de três anos.

\begin{tabular}{|c|c|c|c|c|c|c|c|c|c|c|}
\hline \multirow{3}{*}{ População } & \multicolumn{10}{|c|}{ Produção/planta } \\
\hline & \multicolumn{3}{|c|}{2004} & \multicolumn{3}{|c|}{2005} & \multicolumn{3}{|c|}{2006} & \multirow[t]{2}{*}{ Média } \\
\hline & Média & Mínimo & Máximo & Média & Mínimo & Máximo & Média & Mínimo & Máximo & \\
\hline Caldas Novas & 100 & 1 & 411 & 198 & 0 & 1.287 & 80 & 1 & 320 & 126 \\
\hline Hidrolândia & 107 & 1 & 148 & 113 & 0 & 317 & 403 & 11 & 1.685 & 208 \\
\hline Orizona & 20 & 0 & 86 & 19 & 0 & 130 & 58 & 0 & 304 & 32 \\
\hline Mambai & 164 & 62 & 415 & 257 & 60 & 500 & 347 & 48 & 645 & 256 \\
\hline Damianópolis & 32 & 0 & 135 & 68 & 0 & 255 & 33 & 0 & 201 & 44 \\
\hline Alvorada & 1 & 0 & 9 & 3 & 0 & 15 & 19 & 0 & 268 & 8 \\
\hline Formoso & 37 & 0 & 107 & 88 & 4 & 400 & 146 & 24 & 532 & 90 \\
\hline Estrela do Norte & e 194 & 0 & 588 & 291 & 0 & 1.750 & 6.178 & 0 & 2.122 & 350 \\
\hline Mutunópolis & 15 & 0 & 102 & 70 & 0 & 350 & 1.767 & 2 & 726 & 87 \\
\hline Araguapaz I & 89 & 0 & 41 & 237 & 0 & 905 & 409 & 0 & 1.725 & 218 \\
\hline Araguapaz II & 70 & 0 & 263 & 82 & 0 & 336 & 342 & 87 & 2.160 & 165 \\
\hline Faina & 238 & 0 & 951 & 119 & 0 & 660 & 122 & 6 & 268 & 160 \\
\hline Iporá I & 101 & 0 & 505 & 38 & 0 & 204 & 141 & 0 & 563 & 85 \\
\hline Iporá II & 75 & 0 & 350 & 54 & 0 & 192 & 155 & 40 & 340 & 94 \\
\hline Paraúna & 129 & 0 & 565 & 6 & 0 & 52 & 47 & 3 & 23 & 61 \\
\hline Total & 83 & 0 & 951 & 110 & 0 & 1.750 & 205 & 0 & 2.160 & 132 \\
\hline
\end{tabular}

TABELA 2- Diâmetro do tronco na altura da base (DAB) e na altura do peito (DAP), altura total da planta (ATP) e do início da copa (AIC), área de projeção da copa (APC), número de frutos por planta (NFP) e por $\mathrm{m}^{2}$ de projeção de copa $\left(\mathrm{NF} \mathrm{m}^{-2}\right.$ ) de pequizeiro (Caryocar brasiliense), no Estado de Goiás (média de três anos).

\begin{tabular}{|c|c|c|c|c|c|c|c|c|}
\hline \multirow[b]{2}{*}{ Áreas } & \multirow{2}{*}{$\begin{array}{l}\text { Número } \\
\text { de plantas }\end{array}$} & \multicolumn{7}{|c|}{ Variáveis (média) } \\
\hline & & $\mathrm{DAB}(\mathrm{m})$ & $\mathrm{DAP}(\mathrm{m})$ & $\operatorname{ATP}(\mathrm{m})$ & $\begin{array}{l}\text { AIC } \\
(\mathrm{m})\end{array}$ & $\operatorname{APC}\left(m^{2}\right)$ & NFP (un) & $\mathrm{NF} \mathrm{m}^{-2}$ \\
\hline Caldas Novas & 15 & 0,45 & 0,40 & 7,77 & 2,72 & 93,54 & 126 & 1,35 \\
\hline Hidrolândia & 15 & 0,31 & 0,27 & 5,91 & 2,21 & 58,63 & 2078 & 3,54 \\
\hline Orizona & 15 & 0,27 & 0,22 & 6,65 & 3,73 & 37,89 & 32 & 0,86 \\
\hline Mambaí & 15 & 0,51 & 0,47 & 9,47 & 3,85 & 122,73 & 256 & 2,09 \\
\hline Damianópolis & 15 & 0,37 & 0,33 & 7,12 & 2,96 & 83,47 & 44 & 0,53 \\
\hline Alvorada & 15 & 0,57 & 0,48 & 10,11 & 4,41 & 127,61 & 8 & 0,06 \\
\hline Formoso & 15 & 0,38 & 0,33 & 7,51 & 2,67 & 76,91 & 90 & 1,17 \\
\hline Estrela Norte & 13 & 0,49 & 0,43 & 8,01 & 2,34 & 101,37 & 35060 & 3,45 \\
\hline Mutunópolis & 15 & 0,33 & 0,30 & 8,09 & 4,25 & 79,90 & 87 & 1,09 \\
\hline Araguapaz I & 15 & 0,31 & 0,28 & 6,39 & 2,52 & 62,75 & 218 & 3,47 \\
\hline Araguapaz II & 15 & 0,42 & 0,36 & 8,02 & 2,24 & 88,52 & 165 & 1,86 \\
\hline Faina & 15 & 0,46 & 0,43 & 8,97 & 2,64 & 127,49 & 160 & 1,25 \\
\hline Iporá I & 15 & 0,42 & 0,35 & 7,49 & 2,65 & 84,52 & 85 & 1,00 \\
\hline Iporá II & 15 & 0,35 & 0,30 & 7,30 & 2,91 & 56,95 & 94 & 1,66 \\
\hline Paraúna & 15 & 0,32 & 0,28 & 5,95 & 2,39 & 50,34 & 61 & 1,21 \\
\hline Média & - & 0,40 & 0,35 & 7,64 & 2,97 & 83,34 & 132 & 1,64 \\
\hline CV (\%) & & 27 & 30 & 21 & 34 & 52 & 112 & - \\
\hline
\end{tabular}


TABELA 3- Análise conjunta de variância para a produção de frutos de pequi (Caryocar brasiliense) nos anos avaliados, no Estado de Goiás.

\begin{tabular}{lcc}
\hline \multicolumn{1}{c}{ Fontes de Variação } & GL & QM \\
\hline Anos & 2 & $61574,32^{* *}$ \\
Pop & $(14)$ & $26429,58^{* *}$ \\
Reg & 4 & $53712,44^{\text {ns }}$ \\
Pop/reg & 10 & $15516,44^{* *}$ \\
Pop x anos & $(28)$ & $9047,22^{* *}$ \\
Reg x Anos & 8 & $24082,95^{* *}$ \\
Pop/Reg x Anos & 20 & $3032,93^{\text {ns }}$ \\
Residuo médio/r & 624 & 2952,92 \\
\hline CV $(\%)$ & & 158,29 \\
\hline
\end{tabular}

** Significativo ao nível de $1 \%$ de probabilidade

TABELA 4-Resumo da análise de variância para o número de frutos por planta de pequizeiro (Caryocar brasiliense) no Estado de Goiás.

\begin{tabular}{lccccccc}
\hline \multirow{2}{*}{ Fontes de Variação } & \multirow{2}{*}{ GL } & \multicolumn{6}{c}{ QM } \\
\cline { 3 - 8 } & & 2004 & $\mathrm{CV}(\%)$ & 2005 & $\mathrm{CV}(\%)$ & 2006 & $\mathrm{CV}(\%)$ \\
\hline Populações & $(14)$ & $67210,13^{* *}$ & & $125582,04^{* *}$ & $445242,59^{* *}$ & \\
Regiões & 4 & $19280,32^{\mathrm{NS}}$ & 41,00 & $93549,87^{\mathrm{NS}}$ & 67,00 & $354088,91^{\mathrm{NS}}$ & 75,34 \\
Pop/Regiões & 10 & $86382,06^{* *}$ & 15,05 & $138394,91^{*}$ & 4,65 & $481704,06^{* *}$ & 5,37 \\
Plantas/Pop. & 208 & 14278,11 & 43,94 & 36093,44 & 27,88 & 81160,66 & 19,29 \\
\hline
\end{tabular}

**significativo a $1 \%$, pelo teste $\mathrm{F}$.

TABELA 5- Matriz de correlação residual (acima da diagonal) e total (abaixo da diagonal) entre as variáveis de diâmetro na altura da base (DAB), diâmetro na altura do peito (DAP), altura total da planta (ATP), altura do início da copa (AIC), área de projeção da copa (APC) e número de frutos por planta (NFP) de pequi (Caryocar brasiliense), no Cerrado do Estado de Goiás (média de três anos).

\begin{tabular}{lcccccc}
\hline Variável & DAB $(\mathrm{m})$ & DAP $(\mathrm{m})$ & ATP $(\mathrm{m})$ & AIC $(\mathrm{m})$ & APC $\left(\mathrm{m}^{2}\right)$ & NFP (un) \\
\hline DAB $(\mathrm{m})$ & &, $8528^{* *}$ &, $7032^{* *}$ & $0,1876^{* *}$ & $0,7509^{* *}$ & $0,3753^{* *}$ \\
DAP (m) & $0,9881^{* *}$ & &, $6781^{* *}$ & $0,2131^{* *}$ & $0,7327^{* *}$ & $0,3145^{* *}$ \\
ATP (m) & $0,8983^{* *}$ & $0,9028^{* *}$ & & $0,4667^{* *}$ & $0,7161^{* *}$ & $0,2904^{* *}$ \\
AIC (m) & $0,2627^{* *}$ & $0,2549^{* *}$ & $0,5010^{* *}$ & & $0,1320^{* *}$ & $-0,0694^{\text {ns }}$ \\
APC (m $\left.{ }^{2}\right)$ & $0,9260^{* *}$ & $0,9526^{* *}$ & $0,9232^{* *}$ & $0,2412^{* *}$ & & $0,4469^{* *}$ \\
NFP (un) & $0,2273^{* *}$ & $0,2925^{* *}$ & $0,2502^{* *}$ & $-0,3380^{* *}$ & $0,4032^{* *}$ & \\
\hline
\end{tabular}

$\mathrm{n}=223$ por ano; $* *$ : significativo a $1 \%$ de probabilidade; ns: não significativo. 


\section{CONCLUSÕES}

A produção do pequizeiro, no Estado de Goiás, é irregular entre safras, plantas e populações.

O número de frutos por planta está positivamente correlacionado à maioria das variáveis relacionadas ao porte da planta.

As três populações mais produtivas são de Hidrolândia, Araguapaz e Estrela do Norte, que apresentam como características comuns o vigor, por estarem localizadas em ambiente aberto e por apresentarem início da copa mais próxima do solo.

Há um elevado grupo de organismos que interagem com o pequizeiro, destacando-se os insetos, fungos e aves (araras), que podem influenciar negativamente sobre a produção de frutos.

A alta variabilidade indica a existência de plantas geneticamente promissoras para futuros programas de melhoramento do pequizeiro.

\section{AGRADECIMENTOS}

Ao $\mathrm{CNPq}$ pelo apoio financeiro para a execução do trabalho, pela bolsa de doutorado concedida a primeira autora e de PQ concedida a LJC.

\section{REFERÊNCIAS}

ANJOS, J.R.N.; CHARCHAR, M. J.A.; AKIMOTO, A. K. Ocorrência de antracnose causada por Colletotrichum acutatum em pequizeiro no Distrito Federal. Fitopatologia Brasileira, Brasília, v.27, n.1, p.96-98. 2002.

BORGES, L.M.; REZENDE, A.V.; NOGUEIRA, G.S. Avaliação da amostragem aleatória de ramos para quantificar a produção de frutos de Caryocar brasiliense Camb. (Caryocaraceae). Ciência Florestal, Santa Maria, v. 22, n. 1, p. 113-124, 2012.

CEASA - Central de Abastecimento de Goiás. Análise conjuntural 2011. Disponível em: $<\mathrm{http}: / /$ www.ceasa.goias.gov.br>. Acesso em: 10 dez. 2012.

CÔRREA, G. C.; NAVES, R. V.; ROCHA, M. R. da; CHAVES, L. J.; BORGES, J. D. Determinações físicas em frutos e sementes de baru (Dipteryx alata Vog.), cajuzinho (Anacardium othonianum Rizz.) e pequi (Caryocar brasiliense Camb.), visando ao melhoramento genético. Bioscience Journal, Uberlândia, v. 24, n. 4, p. 42-47, 2008.

GAZETTA, E.; GALETI, M. Ecologia das ervasde-passarinho. Ciência Hoje, São Paulo, v.3, n. 94, p.72-74. 2003.
LOBATO, E.J.V.; ALEIXO, V.; GONÇALVES, V.A.; SACRAMENTO, G.L.; ANDRADE, R.S. Atlas climatológico do Estado de Goiás. Goiânia: CEGRAF/UFG, 2002. 55p.

MELO JÚNIOR, A.F.; CARVALHO, D.; POVOA, J. S. R.; BEARZOTI, E. Estrutura genética de populações naturais de pequizeiro (Caryocar brasiliense Camb.). Scientia Forestalis, São Paulo, n.66, p.56-65. 2004.

MESQUITA, M.A. M.; NAVES, R. V.; SOUZA, E.R.B.; BERNARDES, T.G.; SILVA, L.B. Caracterização de ambientes com alta ocorrência natural de araticum (Annona crassiflora Mart.) no Estado de Goiás. Revista Brasileira de Fruticultura, Jaboticabal, v.29, n.1, p. 15-19. 2007.

MOURA, N. F.; CHAVES, L. J.; NAVES, R. V. Caracterização física de frutos de pequizeiro (Caryocar brasiliense Camb.) do Cerrado. Revista Árvore, Viçosa, MG, v. 27, n. 5, p. 905-912. 2013 a.

MOURA, N. F.; CHAVES, L. J.; NAVES, R. V.; AGUIAR, A. V.; SOBIERAJSKI, G. R. Variabilidade entre progênies e procedências de pequizeiro (Caryocar brasiliense Camb.). Scientia Forestalis, Piracicaba, v. 41, n. 97, p. 103-112. 2013 b.

RIBEIRO, J.F.; WALTER, B.M.T. As principais fitofisionomias do Bioma Cerrado. In. SANO, S.M.; ALMEIDA, S.P.; RIBEIRO, J.F. (Ed.). Cerrado: Ecologia e Flora. Brasília: Embrapa Cerrados, Informações Tecnológica, 2008. p.151-212.

SANTANA, J. das G.; NAVES, R.V. Caracterização de ambientes de cerrado com alta densidade de pequizeiros (Caryocar brasiliense Camb.) na região sudeste do Estado de Goiás. Pesquisa Agropecuária Tropical, Goiânia, v. 33, n.1, p. 1-10, 2003.

VERA, R.; SOUZA, E.R.B.; FERNANDES, E.P.; NAVES, R.V.; SOARES JÚNIOR, M.S.; CALIARI, M.; XIMENES, P. A. Caracterização física e química de frutos do pequizeiro(Caryocar brasiliense Camb.) oriundos de duas regiões no Estado de Goiás, Brasil. Pesquisa Agropecuária Tropical, Goiânia, v. 37, n. 2, p. 93-99, 2007.

VILELA, G.F.; CARVALHO, D. de; VIEIRA, F. de A. Fenologia de Caryocar brasiliense Camb. (Caryocaraceae) no alto Rio Grande, sul de Minas Gerais. Cerne, Lavras, v. 14, n. 4, p. 317-329, 2008. 